\title{
Lipid Transfer Protein Syndrome in a Non-Mediterranean Area
}

Julian Azofra ${ }^{a}$ Felicia Berroa ${ }^{c}$ Gabriel Gastaminzac ${ }^{c}$ Noemi Saiz ${ }^{\mathrm{e}}$

Pedro M. Gamboa ${ }^{f}$ Catalina Vela $^{d}$ Blanca E. García ${ }^{d}$ Susana Lizarza ${ }^{f}$

Miguel Angel Echenagusia ${ }^{g} \quad$ Alejandro Joral $^{f}$ María Ascensión Aranzabal ${ }^{\mathrm{h}}$

Maria Dolores Quiñones ${ }^{b}$ Ignacio Jauregui ${ }^{f}$ Juan F. Madera ${ }^{i}$

Jose Antonio Navarro ${ }^{f}$ Maria Teresa Lizaso ${ }^{d}$ Amalia Bernad ${ }^{c}$

Maria José Goikoetxea ${ }^{c}$

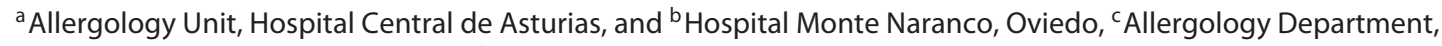
Clínica Universidad de Navarra, and d Allergology Department, Complejo Hospitalario de Navarra, Pamplona, eAllergology Department, Hospital del Bierzo, Ponferrada, ${ }^{\mathrm{f} A l l e r g o l o g y ~ S e r v i c e, ~ H o s p i t a l ~ d e ~ B a s u r t o, ~ B i l b a o, ~}$

${ }^{f}$ Allergology Service, Hospital Universitario Donostia, San Sebastián, ${ }^{9}$ Allergology Unit, Hospital de Mendaro, Mendaro, and ${ }^{\mathrm{h}}$ Allergology Unit, Hospital de Zumárraga, Zumárraga, Spain

\section{Key Words}

Clinical characterization - Lipid transfer protein syndrome · Non-Mediterranean area

\footnotetext{
Abstract

Background: Plant food allergies associated with lipid transfer protein (LTP) have been widely described in the Mediterranean Basin. Objective: The aim of this work was to describe the clinical profile and pollen sensitization of plant foodallergic patients sensitized to LTP in a non-Mediterranean area. Methods: Patients with clear IgE-mediated symptoms associated with plant foods and a positive skin prick test (SPT) to Pru p 3 were included in a prospective study in the north of Spain. Reported symptoms were analyzed together with a battery of food and pollen SPTs and specific IgE components by ISAC microarray. Cross-inhibition studies were
}

\section{KARGER}

E-Mail karger@karger.com www.karger.com/iaa performed by ImmunoCAP with plane tree, mugwort and rPru p 3. Results: Among the 72 patients included, the most frequent food allergy reported was to peaches (69\%) followed by nuts (walnuts $55 \%$, peanuts $54 \%$ and hazelnuts $43 \%$ ). Most patients suffered from symptoms with multiple plant foods (a median of 6 foods per patient). Regarding the patients' pollen sensitization, $36 \%$ were sensitized to mugwort pollen ( $72 \%$ showing slgE to Art v 3 ), $33 \%$ to grass pollen and $24 \%$ to plane tree pollen (94\% with slgE to Pla a 3). Inhibition studies showed that specific IgEs against mugwort and plane tree pollen are inhibited by Pru $\mathrm{p} 3$ in a strong manner, whereas Pru p 3 was less inhibited by pollen extracts. Conclusions: LTP syndrome occurs in a non-Mediterranean area and is related to multiple sensitizations to foods and pollens such as plane tree and mugwort. In these pollen sensitizations, Pru p 3 seems to be the primary sensitizer.

๑) 2016 S. Karger AG, Basel (c) 2016 S. Karger AG, Basel

$1018-2438 / 16 / 1693-0181 \$ 39.50 / 0$
Correspondence to: Dr. Gabriel Gastaminza

Allergology Department, Clínica Universidad de Navarra Pio XII, 36

ES-31008 Pamplona (Spain)

E-Mail mjgoiko@unav.es 


\section{Introduction}

In 1992 Lleonart et al. [1] described a small 8- to 10$\mathrm{kDa}$ protein as the major allergen affecting peach-allergic patients in Spain. This allergen, characterized as a lipid transfer protein (LTP), is now an unquestionably relevant allergen and the most frequent cause of primary food allergies in adults living in the Mediterranean area [2-6]. LTPs can be included in the huge prolamin protein superfamily. They are thought to play a functional defensive role against phytopathogens (bacteria, fungi) in plants. LTPs are widespread in different plant foods and pollens, and, considered as a panallergen, are responsible for allergic reactions [7-9]. LTPs are highly resistant to both heat treatment and proteolytic digestion [10], which are characteristics associated with the induction of severe symptoms. However, cases of oral allergy syndrome (OAS) have also been reported in LTP-sensitized plant food-allergic patients [11].

LTPs are highly conserved and widely distributed throughout the plant kingdom. More importantly, several LTPs have high cross-reactivity among them [12], frequently causing LTP-sensitized patients to have multiple sensitizations and clinically relevant allergies to different plant foods; a situation that has been termed the LTP syndrome [13]. Rosacea fruits and nuts are the main plant food allergens involved in this syndrome [13, 14]. LTPs have also been described in pollens such as mugwort (Art v 3), plane tree (Pla a 3), Parietaria judaica (Par j 2) and olive tree (Ole e 7) pollens. However, these last two LTPs seem to have no cross-reactivity with allergenic plant food LTPs since Pru 33 shares epitopes with LTPs from many fruits, nuts and vegetables, and even with mugwort, but not with Par j 2 [15] or Ole e 7 [16], suggesting that neither of these two pollens are linked to the LTP syndrome [17]. The existence of areas with a prevalence of plant food allergies where LTP sensitization is relevantly colocalized with LTP-enriched pollens suggests that pollinosis could trigger Pru p 3 sensitization [18-20].

Although LTP sensitization is not frequent in Central Europe, it does exist [20]. Both the pollinosis and climatology of the north of Spain differ in comparison to Mediterranean Spain, and are aerobiologically close to Central Europe but with similar characteristics to those of Mediterranean regions.

Based on the common link between food allergies and palynology, as well as on the latter's dependence on meteorology, it is important to note that the climate of the studied region is of the Atlantic type, and is therefore de- fined by a high average annual rainfall $\left(1,000-1,500 \mathrm{~mm}^{3} /\right.$ year). The region's pollen load is mainly comprised of grass pollen, with a light-to-moderate presence of pollen from the Betulaceae family (birch trees), and a total absence of pollen from Artemisia, Parietaria and Olea genera. Although the Oleaceae species Fraxinus excelsior is present in the region, it differs from the common Mediterranean species, and could be considered an intermediate species between the common species and those located in Central-Northern Europe. Contrastingly, the average annual rainfall is much lower in the Mediterranean Basin (approx. $500 \mathrm{~mm}^{3} /$ year), and the region's pollen load is marked by a significant presence of grass pollen, but also by elevated concentrations from olive trees and species of the Parietaria genus, with a light-to-moderate presence of mugwort and plane tree pollen. In Spain, LTP sensitization is reported to be the most prevalent sensitization among peach-allergic patients of the study region [21]. Likewise, and despite the climatic differences between the northern and central/southern regions of the country, a similar LTP sensitization is observed in Italian patients suffering from anaphylaxis [6]. However, no wide series of LTP-sensitized patients have been described in Mediterranean countries with a non-Mediterranean climatology. The goal of this study is to describe the clinical profile of the LTP syndrome in an unusual area with non-LTP-enriched pollens and Mediterranean habits.

\section{Materials and Methods}

A prospective study was carried out from October 2011 to August 2012 in the Allergology Services of the following 8 participating hospitals (to which 18,500 new outpatients attended): Clínica Universitaria de Navarra (Navarre University Clinic; Navarre), Complejo Hospitalario de Navarra (Navarre Hospital Complex; Navarre), Hospital de Mendaro (Gipúzcoa), Hospital de Zumárraga (Guipúzcoa), Hospital Donostia (Guipúzcoa), Hospital de Basurto (Vizcaya), Hospital del Bierzo (León) and Hospital Universitario Central de Asturias (Asturias). The study was previously approved by the ethics committees of the participating hospitals and all the participating patients were informed of the study protocol and were requested to sign a written informed consent form.

Patients

The patients recruited to participate in the study were individuals aged 18 years and older with unequivocal symptoms of a plant food allergy, with sensitization to purified peach LTP, a negative skin prick test (SPT) to date palm profilin and birch pollen, and who had experienced at least one episode of a food allergy within the past 2 years.

The patients' clinical manifestations were grouped into two categories: OAS, defined as the onset of pruritus and/or of an an- 
gioedema of the lips or oral cavity immediately after ingesting allergenic foods, and systemic symptoms, in the case of urticaria/ angioedema, gastrointestinal disorders, rhinitis, conjunctivitis, bronchospasms or circulatory symptoms of anaphylaxis.

\section{Questionnaire}

The patients were provided with a detailed questionnaire that collected their general personal data and other information regarding their food allergy, including the foods that caused them problems, the symptoms they had experienced, the order of the onset of allergic reactions to the different foods, the existence of cofactors associated with the reactions and whether or not they carried autoinjectable epinephrine. The questionnaire can be viewed in the online supplementary material (for all online suppl. material, see www.karger.com/doi/10.1159/000445893).

\section{Skin Tests}

SPTs were performed to assess the patients' reactivity to the following allergens: $99 \%$ purified peach LTP extract (100 mg nPru p 3/ml; Bial-Arístegui, Bilbao, Spain), date palm profilin (nPho d 2), Betula verrucosa, Phleum pratense, A. vulgaris, $P$. judaica, Platanus acerifolia, O. europaea, Cupressus arizonica, Salsola kali, peach, peanut, hazelnut, walnut, sunflower seed, corn, wheat, tangerine, apple, banana, lentil, green bean, tomato, lettuce, onion, kiwi and carrot (ALK-Abelló, Madrid, Spain).

The results were read after approximately $15 \mathrm{~min}$, and the remaining papules were transferred to a sheet of graph paper with the aid of transparent adhesive tape. The readings were performed by a single person and by means of planimetry. Pricks with a total area $\geq 7 \mathrm{~mm}^{2}$ were considered to be positive.

\section{Specific IgE Determination}

The ImmunoCAP FEIA 250 test (Thermo Fisher Scientific, Uppsala, Sweden) was used to determine the presence of specific IgEs against $r$ Pru p 3 . All values $\geq 0.35 \mathrm{kU} / \mathrm{l}$ were considered to be positive. Additionally, the ISAC CRD 112 microarray method (Thermo Fisher Scientific), which provides data on 112 components, was used to determine the patients' reactions to multiple allergenic components, considering an ISU value $\geq 0.3$ as a positive result.

\section{Specific IgE inhibition}

Specific IgE inhibition studies were performed using the ImmunoCAP FEIA 250 test (Thermo Fisher Scientific) with ImmunoCAPs. Sera from 5 patients showing high levels of specific IgE to Pla a 3 (pool A), and 5 other patients with high levels of specific IgE to Art v 3 (pool B) in the microarray were pooled. These sera were inhibited with both rPru $\mathrm{p} 3$ (kindly donated by A. DíazPerales) and plane tree extract or mugwort extract (Bial-Arístegui), respectively, at final concentrations of 12,6 and $2 \mu \mathrm{g} / \mathrm{ml}$ at room temperature for $2 \mathrm{~h}$ for the recombinant allergens, and using the concentrated extract at 1:10 and 1:100 dilutions for pollen extracts. Subsequently, the inhibitor mixtures (including sera with no inhibitor as a positive control) were added to plane tree (t11) and Pru p 3 (f420) ImmunoCAPs in the case of pool A and to mugwort (w6) and Pru p 3 (f420) ImmunoCAPs in the case of pool B. Assay was performed using the manufacturer's protocol. The percentage inhibition of IgE binding was calculated using the following formula: [(kUA/l inhibited - $\mathrm{kUA} / \mathrm{l}$ positive control): $\mathrm{kUA} / \mathrm{l}] \times 100$.

LTP Syndrome in Northern Spain

\section{Statistical Analysis}

All the data obtained were processed using the SPSS statistical package for MAC OS, version 20.0 (SPSS Inc., Chicago, Ill., USA). The qualitative data were expressed in terms of frequencies or percentages. The quantitative data were expressed in terms of median values and the interquartile range (IQR) as distributions were not normal. The normality of variables was determined by means of the Shapiro-Wilk test. The differences between the groups of quantitative variables were assessed using the Mann-Whitney $U$ test, whereas the $\chi^{2}$ (or Fisher's exact test when needed) was used to compare proportions. Spearman's correlation was used to evaluate the association between continuous variables.

\section{Results}

\section{Characteristics of the Sample Population}

A total of 72 patients with an average age of 34 years (IQR 23-39.5) were included in the study, 37 of whom were women $(51.4 \%)$ and 35 were men $(48.6 \%)$. Of this total, $49 \%$ of the patients (35 patients) had a family history of atopy, 43\% (30 patients) suffered from an associated rhinoconjunctivitis, with 15 of these patients also experiencing asthma, and 1 (1.4\%) had developed an atopic dermatitis. The distribution of the participating patients among the clinics located in the studied region was homogeneous. The patient data are summarized in table 1 .

\section{Allergenic Foods}

The total number of foods responsible for allergic symptoms was 68. Peaches accounted for the greatest number of reported reactions (50 patients, 69\%), followed by walnuts $(40,55 \%)$, peanuts $(39,54 \%)$, hazelnuts $(31,43 \%)$, almonds $(29,40 \%)$, kiwifruits $(19,26 \%)$, nectarines $(18,25 \%)$, apples and sunflower seeds $(17,24 \%)$, and apricots, plums and cherries $(15,21 \%)$. The following foods were reported to have caused symptoms in 10-20\% of the participating patients: pistachio, Saturn peach, grape, strawberry, melon, corn, banana, pear and mustard. Approximately 5-10\% of the patients reported having developed an allergic reaction to the following foods: chestnut, cashew, Brazil nut, pine nut, tomato, wheat, pineapple, fig, lettuce, lentil, quince, orange and soya bean. Less than $5 \%$ of the patients experienced symptoms to the following foods: pomegranate, watermelon, leek, garbanzo bean, white bean, pea, green bean, tangerine, medlar fruit, blackberry, mango, cucumber, cacao, cauliflower, garlic, onion, blueberry, avocado, custard apple, lemon, celery, zucchini, sesame seed, endive, chamomile, broccoli, beetroot, potato, pepper, rice, date, nut grass, raspberry and pepper. 
Table 1. Characteristics of the sample

\begin{tabular}{|c|c|c|}
\hline Patients & & 72 \\
\hline \multicolumn{3}{|l|}{ Demographic data } \\
\hline Age, years & & $34(23-39.5)$ \\
\hline Male & & $35(48.6)$ \\
\hline \multicolumn{3}{|l|}{ Clinical data } \\
\hline Family history of atopy & & $51(71)$ \\
\hline Rhinoconjunctivitis & & $30(43)$ \\
\hline Asthma & & $15(21)$ \\
\hline \multirow[t]{2}{*}{ Atopic dermatitis } & & $1(1.4)$ \\
\hline & Positive sIgE & Median \\
\hline \multicolumn{3}{|l|}{ ImmunoCAP results } \\
\hline sIgE to Pru p 3 & $69(96)$ & $3.9(1.4-9.6)$ \\
\hline \multicolumn{3}{|l|}{ ISAC results } \\
\hline sIgE to Pru p 3 & $63(87.5)$ & $1.6(0.7-2.9)$ \\
\hline sIgE to Ara h 9 & $44(61)$ & $0.5(0-1.3)$ \\
\hline sIgE to Jug r 3 & $54(75)$ & $1(0.3-2.3)$ \\
\hline sIgE to Cor a 8 & $31(50)$ & $0.3(0-1.1)$ \\
\hline sIgE to Art v 3 & $18(25)$ & $0.2(0-0.9)$ \\
\hline sIgE to Pla a 3 & $48(67)$ & $0.5(0-1.4)$ \\
\hline sIgE to Par j 2 & $1(1)$ & $0(0-0)$ \\
\hline sIgE to Ole e 7 & $9(12.5)$ & $0(0-0)$ \\
\hline sIgE to Tri a 14 & $6(8)$ & $0(0-0)$ \\
\hline
\end{tabular}

Data are expressed as $\mathrm{n}(\%)$ or median (IQR).

In this sample of peach LTP-sensitized patients, a positive specific IgE to Pru $\mathrm{p} 3$ was not associated to symptoms with peach $(\mathrm{p}=0.268)$. A positive specific IgE against Cor a 8 was also unassociated in those patients reporting symptoms with hazelnut $(\mathrm{p}=0.153)$. However, patients showing symptoms with walnut and wheat more frequently showed a positive specific IgE against their LTPs present in microarray (Jug r $3, p=0.004$, Tri a $14, p=0.017$ ), and patients reporting symptoms with peanut tended to more frequently have a positive specific IgE against Ara h $9(\mathrm{p}=$ $0.058)$, although this was not statistically significant.

Interestingly, the most reported non-Rosacea non-nut allergenic fruit was kiwifruit, representing the fifth cause of symptoms in our population. Among the 19 patients reporting symptoms, only 8 showed a positive SPT, whereas 3 patients showed a positive SPT and tolerated the fruit. Only 4 out of 19 patients having problems with kiwifruit showed sensitization to Act $d 1$. None of them showed sensitization to Act d 2, Act d 5 or Act d 8. Data about symptoms, skin sensitization and specific IgEs against LTPs and other components present in microarrays from the most frequently reported plant foods are summarized in table 2 .
Complexity of the Food Allergies (Number of Foods and Food Groups Involved)

A total of $24 \%$ of the participating patients experienced allergic symptoms with more than 10 foods; $46 \%$ experienced them with 5-9 foods; $25 \%$ with 2-4 foods, and $5 \%$ with only 1 type of food. The resulting median value was of 6 allergenic foods per patient (IQR 4-9). There were no associations between specific IgEs against Pru p 3 (CAP) and the number of the abovementioned allergenic foods involved (Spearman's correlation rho $=$ -0.074; $p=0.326$ ). A subsequent analysis classified these foods into groups following botanical taxonomy. There were no associations between the number of LTPs recognized by a patient and the number of food groups eliciting symptoms in that patient (Spearman's correlation rho $=-0.018 ; \mathrm{p}=0.881$ ) or with the number of offending foods (Spearman's correlation rho = $-0.025 ; \mathrm{p}=0.832$ ).

To simplify, food groups were classified into 4 categories: Rosaceae fruits, nuts, legumes and others. In this case, 12 patients (17\%) experienced allergic symptoms with a single food group ( 6 only developed allergic reactions to the Rosaceae fruits, 3 to nuts, 2 to the food group named 'others' and 1 to legumes), 24 (33\%) experienced them with 2 food groups, 29 (40\%) with 3 food groups and $8(11 \%)$ with all 4 food groups. When comparing specific IgE levels against Pru p 3 (CAP) with these 4 food groups, patients allergic to 2 food groups $(4.47 \mathrm{kUA} / \mathrm{l}$, IQR 3-10) and to 3 food groups (4.85 kUA/l, IQR 2.5-12) showed significantly higher $(\mathrm{p}<0.01)$ specific IgE levels against Pru 3 (CAP) than those showing symptoms with 4 food groups (1.26 kUA/l, IQR 0.4-3). Patients allergic to 1 food group showed $3.4 \mathrm{kUA} / \mathrm{l}$ (IQR 1-20) of specific IgE against Pru p 3.

\section{Symptomatology}

Out of all the study patients, 69 (96\%) developed systemic symptoms and $62(86.1 \%)$ experienced an OAS. An OAS was reported as the sole manifestation of the food allergy in 3 cases (4\%), whereas systemic symptoms were described as the only allergic reaction in 10 cases (14\%).

\section{Relationship between the Symptomatology and the Type of Food}

The 5 allergenic foods that were most frequently involved in the clinical manifestation of both an OAS and systemic symptoms were those that were previously described as the most common allergenic foods. These were, in decreasing order: peaches, nuts, peanuts, hazelnuts and almonds. 


\section{Cofactors}

The existence of an associated cofactor was detected in 15 patients $(21 \%)$. In 11 of these cases the cofactor corresponded to physical exercise, and in another 5 cases it consisted of the intake of NSAIDs (1 patient reported that his allergic reactions were associated with both cofactors). Nuts were the allergenic foods most frequently associated with the onset of symptoms linked to these cofactors.

\section{Characteristics of the Peach Allergy}

Of the 50 peach-allergic patients, $12(24 \%)$ tolerated the fruit after it had been peeled. As for its symptomatology, 26 patients (52\%) developed contact urticaria, 47 (94\%) an OAS and 35 (70\%) had systemic symptoms.

Among the 22 patients sensitized to peach LTP who did not report symptoms with peach, 10 did not eat peach and 12 tolerated it, 2 even with the skin and 10 only when peeled. Five of the 12 peach-tolerant, LTP-sensitized patients showed symptoms with Rosacea other than peach. Only 1 LTP-sensitized patient was also sensitized to Pru p 1, even showing a negative birch SPT. Similar specific IgEs to Pru p 3 (CAP), numbers of offending foods and groups of foods were reported between patients showing symptoms with peach and those who did not report problems. These similarities were also observed between those patients who tolerated peach and those with unknown tolerance.

\section{Time Sequence of the Onset of the Food Allergies}

In 40 cases $(55.5 \%)$, peaches were the first food to cause allergic symptoms, followed by nuts $(17,24 \%)$, other fruits from the Rosaceae family $(5,7 \%)$ and other plants $(9,12.5 \%)$.

\section{Sensitization to Pollens and Their Components}

Table 2 sets out the results of the sensitizations detected against the different types of pollen, including the number and percentage of patients with positive results for each one of their allergenic components. The main pollen sensitization was grass, a common pollen in this area, followed by mugwort and plane tree pollen. Whereas grass pollen sensitization was associated with the major allergen Phl p $1(\mathrm{p}<0.0001)$, mugwort and plane tree pollen sensitizations were associated with their LTPs (Art v 3, p $<0.001$, and Pla a 3, p = 0.007).

\section{Specific IgE Inhibition against Mugwort and Plane \\ Tree Pollen}

Inhibition studies showed that specific IgEs against mugwort and plane tree pollen are inhibited by Pru p 3 in
Table 2. Sensitization to pollen and food by SPT, symptoms and allergen microarray ISAC

\begin{tabular}{|c|c|c|c|c|c|}
\hline \multicolumn{3}{|l|}{ Pollen } & $\begin{array}{l}\text { SPT- } \\
\text { positive } \\
\text { patients, n }\end{array}$ & $\begin{array}{l}\text { sIgE } \\
\text { (ISAC) }\end{array}$ & $\begin{array}{l}\text { Sensitized } \\
\text { patients, n } \\
(\%)\end{array}$ \\
\hline \multirow{8}{*}{\multicolumn{3}{|c|}{ Grasses }} & \multirow[t]{8}{*}{26} & Phl p 1 & $16(61.5)$ \\
\hline & & & & Phl p 2 & $10(38)$ \\
\hline & & & & Phl p 4 & $10(38)$ \\
\hline & & & & Phl p 5 & 7 (27) \\
\hline & & & & Phl p 6 & $5(19)$ \\
\hline & & & & Phl p 7 & $2(8)$ \\
\hline & & & & Phl p 11 & $5(19)$ \\
\hline & & & & Phl p 12 & $0(0)$ \\
\hline \multirow{2}{*}{\multicolumn{3}{|c|}{ Mugwort (A. vulgaris) }} & 25 & Art v 1 & $1(4)$ \\
\hline & & & & Art $v 3$ & $18(72)$ \\
\hline \multirow{3}{*}{\multicolumn{3}{|c|}{ Plane tree $(P$. acerifolia $)$}} & 17 & Pla a 1 & $2(12)$ \\
\hline & & & & Pla a 2 & $6(35)$ \\
\hline & & & & Pla a 3 & $16(94)$ \\
\hline \multirow{3}{*}{\multicolumn{3}{|c|}{ Olive tree (O. europaea) }} & 9 & Ole e 1 & $3(33)$ \\
\hline & & & & Ole e 7 & $2(22)$ \\
\hline & & & & Ole e 9 & $1(11)$ \\
\hline \multicolumn{3}{|c|}{ Prickly saltwort (S. kali) } & 7 & Sal k 1 & $0(0)$ \\
\hline \multicolumn{3}{|c|}{ Pellitory of the wall (Parietaria sp.) } & 5 & $\operatorname{Parj} 2$ & $1(20)$ \\
\hline \multicolumn{3}{|c|}{ Cypress (C. arizonica) } & 4 & Cup a 1 & $3(75)$ \\
\hline Foods & $\begin{array}{l}\text { Symptomatology } \\
\text { reported, } \mathrm{n}\end{array}$ & SPT, n & $\begin{array}{l}\text { sIgE } \\
\text { (ISAC) }\end{array}$ & \multicolumn{2}{|c|}{$\begin{array}{l}\text { Patients reporting } \\
\text { symptoms, } \mathrm{n}(\%)\end{array}$} \\
\hline \multirow[t]{2}{*}{ Peach } & 50 & 70 & Pru p 1 & \multirow{2}{*}{\multicolumn{2}{|c|}{$\begin{array}{c}1(1) \\
43(87.5)\end{array}$}} \\
\hline & & & Prup 3 & & \\
\hline \multirow[t]{3}{*}{ Walnut } & 40 & 50 & Jug r 1 & \multirow{3}{*}{\multicolumn{2}{|c|}{$\begin{array}{c}1(1) \\
4(5.5) \\
36(75)\end{array}$}} \\
\hline & & & Jug r 2 & & \\
\hline & & & Jugr 3 & & \\
\hline \multirow[t]{6}{*}{ Peanut } & 39 & 48 & Ara h 1 & \multicolumn{2}{|l|}{$0(0)$} \\
\hline & & & Ara h 2 & \multicolumn{2}{|l|}{$0(0)$} \\
\hline & & & Ara h 3 & \multicolumn{2}{|l|}{$0(0)$} \\
\hline & & & Ara h 6 & \multicolumn{2}{|l|}{$4(5.5)$} \\
\hline & & & Ara h 8 & \multicolumn{2}{|l|}{$0(0)$} \\
\hline & & & Ara h 9 & \multicolumn{2}{|l|}{$27(61)$} \\
\hline Hazelnut & 31 & 48 & Cor a 8 & \multicolumn{2}{|l|}{$19(50)$} \\
\hline \multirow[t]{4}{*}{ Kiwi } & 19 & 13 & Act d 1 & \multicolumn{2}{|l|}{$4(21)$} \\
\hline & & & Act d 2 & \multicolumn{2}{|l|}{$0(0)$} \\
\hline & & & Act d 5 & \multicolumn{2}{|l|}{$0(0)$} \\
\hline & & & Act d 8 & \multicolumn{2}{|l|}{$0(0)$} \\
\hline Wheat & 3 & 2 & Tri a 14 & $2(8)$ & \\
\hline
\end{tabular}

LTPs are italicized. 
Fig. 1. Inhibition studies. The percentages of specific IgE inhibition against plane tree and Pru $\mathrm{p} 3$ were inhibited with different concentrations of Pru p 3 and plane tree extract, respectively, for 5 pooled patients sensitized to Pla a 3 (black lines). The percentages of specific IgE inhibition against mugwort and Pru p 3 were inhibited with Pru p 3 and mugwort extract, respectively, for 5 pooled patients sensitized to Art v 3 (gray lines).

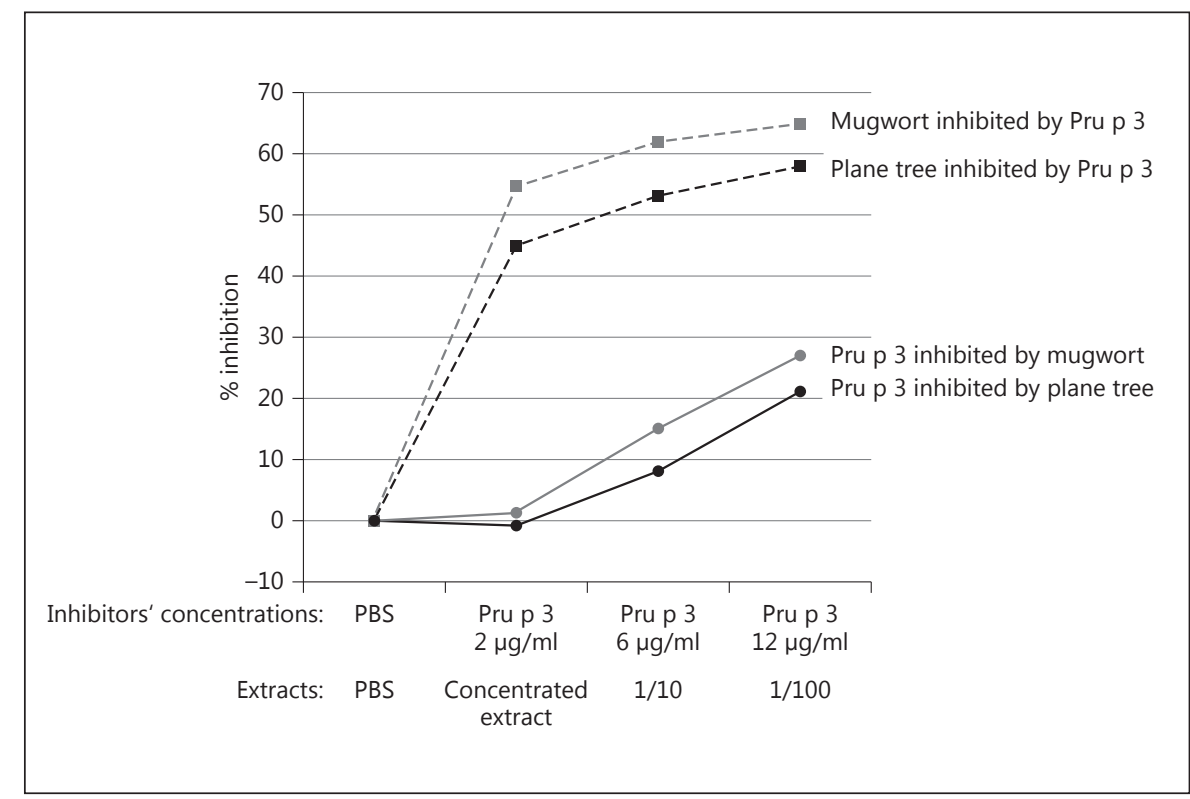

a strong manner. However, pollen extracts (mugwort and plane tree) showed lower percentages of Pru p 3 inhibition. These data are presented in figure 1.

\section{Carriers of Autoinjectable Epinephrine}

Out of the 72 study patients, 34 carried autoinjectable epinephrine. Only $44 \%$ of the patients who had experienced systemic symptoms in the past carried the device.

\section{Discussion}

LTP sensitization seems to be a special hallmark of the Mediterranean area, a region where a so-called LTP syndrome has even been defined [13]. The goal of this study was to characterize this syndrome in the north of Spain, a geographical region that differs greatly from that of the Mediterranean Basin.

The study was limited to patients with an unequivocal history of food allergies, a positive SPT to a purified LTP extract from peach, and a negative sensitization to other panallergens, such as PR-10 proteins and profilins. We are well aware of the fact that our study does not include the gold standard for the diagnosis of food allergies, the DBPCFC. However, the prospective inclusion of patients with an unequivocal clinical history of an IgE-mediated process is similar to that of other studies involving LTPsensitized patients $[8,9,19,20,22,23]$. Additionally, the frequency with which the patients developed systemic symptoms, as well as the large number of foods that triggered the onset of allergic symptoms in each patient, constitute a major constraint for a DBPCFC-type study design.

Despite the fact that the study was carried out on adult patients, we must note that these were mainly young patients with an average age of 34 years, which is very similar to that of the patients involved in other studies (patients between the ages of 29 and 37 years) $[8,22,23]$ and with a high incidence of atopy ( $43 \%$ with rhinitis and $21 \%$ with asthma), as is also mentioned in the referenced literature [24].

Our study patients experienced immediate allergic reactions to an extremely diverse range of foods, including 68 different plants, with a resulting median value of 6 symptomatic plant foods per patient, and with Rosaceae fruits and nuts accounting for the highest number of allergic reactions, which are very similar results to those published in other studies conducted in the Mediterranean region $[8,25]$. These data are suggestive of the ubiquity of the presence of LTPs in our usual diet and of the high degree of cross-reactivity between these proteins. Moreover, the extensive sensitization to different LTPs observed in our patients, independent of symptoms, supports the assertion of this high degree of cross-reactivity. Nevertheless, there seems to be variations in the individual response to its different molecular epitopes, which leads to the existence of significant differences between different food allergies [8]. Levels of specific IgE to Pru p 
3 have been reported as a biomarker to asses these differences [26]. Unfortunately, in our experience, specific IgE levels against Pru p 3 were not correlated with an allergy to different sorts of foods, and neither was the number of positive LTPs in the microarray associated with food allergy complexity. Furthermore, the most complex allergy observed (those patients having symptoms with four groups of food, i.e. Rosacea, nuts, legumes and other vegetables) showed lower levels of specific IgE to Pru p 3, maybe due to an extensive food restriction.

The high incidence of allergic reactions to kiwifruit among our study patients (26\%) must also be noted (only 4/19 were sensitized to Act d 1 and no other sensitization to kiwifruit components has been demonstrated). The kiwifruit is not a plant food that is commonly associated with LTP sensitization $[8,14]$ in other series, although kiwifruit allergies with sensitization to its LTP Act d 10 have been reported in $22 \%$ of cases from Southern Europe [27]. Although the kiwifruit LTP seems to have slightly different properties than those of the classic LTPs [28], without overlooking the new and emerging kiwifruit allergens [29], we cannot dismiss the possibility that our patients reporting symptoms with kiwifruits could be sensitized to the LTP Act d 10. However, our data cannot draw any conclusions in this sense.

The prevalence of peach as an allergic symptom-inducing food, having been reported by $70 \%$ of the study patients and with a much higher frequency than that of the other foods, was the expected result, as a positive SPT to purified Pru p 3 was the inclusion criterion. However, as opposed to the report by Asero et al. [25], in our study we could not determine that the levels of Pru p 3 correlated with the number of foods involved in the allergic reactions.

Practically all the participating patients (96\%) developed systemic reactions after ingesting these foods, and only 3 patients experienced an OAS as the only clinical manifestation of their allergy, which reflects other published results [19], based on the stability reported for the protein. The presence of cofactors (physical exercise, intake of NSAIDs, etc.) in $21 \%$ of the study patients is lower than other published values [19].

In most of these cases (55\%), peaches were the first food to cause an allergic reaction in the study patients, followed by nuts (24\%). Although peaches are generally considered to be the plant food that initiates this syndrome, cohort studies analyzing the temporary evolution of this allergy are few [30, 31].

Spain is the fourth largest peach producer in the world and the second largest producer within the European
Union after Italy, with $70 \%$ of the produce being consumed as fresh fruit. Furthermore, it has been suggested that the inhalation of pollens containing LTP, such as mugwort and plane tree pollens, by populations that are highly exposed to them, could be the underlying cause of their sensitization $[18,32,33]$. However, our results support the food-borne origin of the sensitizations, as our patients' sensitizations to mugwort and plane tree pollens were almost exclusively caused by the LTP contained in them (Art v 3 and Pla a 3, respectively) and specific IgE against these pollens in patients sensitized to their LTPs was inhibited by Pru p 3. Furthermore, Pru p 3 as an inhibitor was stronger than extracts as inhibitors in crossinhibition assays, although these differences could be due to the use of extracts instead of the pure molecule Art v 3 and Pla a 3. Thus, given the absence of mugwort pollen in the study region, and based on the rare presence of plane tree pollen, we believe that this sensitization is caused by cross-reactivity with Pru p 3, which would act as a primary sensitizer.

In short, we have provided the largest series of patients with an LTP syndrome described so far, and in a geographical area other than that of the Mediterranean Basin. Our patients' profiles are very similar to those of Mediterranean patients, where the sensitization is more prevalent, and we therefore reject the hypothesis that the type of pollination is causally related with the sensitization in this region.

\section{Acknowledgements}

This study was partially funded by Fundación Jesús Gangoiti y Barrera, and Alergonorte. We thank Paul Miller for his invaluable help in reviewing the language of the manuscript, Maria Angeles Salgado and Sonia Ariz for their wonderful technical work, and Araceli Díaz-Perales for providing rPru p 3 for the inhibition assays. G.G. and M.J.G. belong to the Spanish Research Network on Adverse Reactions to Allergens and Drugs (RIRAAF, Red de Investigación de Reacciones Adversas a Alérgenos y Fármacos) of the Carlos III Health Institute.

References

1 Lleonart R, Cisteró A, Carreira J, Batista A, Moscoso del Prado J: Food allergy: identification of the major IgE-binding component of peach (Prunus persica). Ann Allergy 1992;69: 128-130.

2 Asero R, Antonicelli L, Arena A, Bommarito L, Caruso B, Crivellaro M, et al: Epidem AAITO: features of food allergy in Italian adults attending allergy clinics: a multi-centre study. Clin Exp Allergy 2009;39:547-555. 
3 Fernández-Rivas $\mathrm{M}$, Bolhaar $\mathrm{S}$, GonzálezMancebo E, Asero R, van Leeuwen A, Bohle B, et al: Apple allergy across Europe: how allergen sensitization profiles determine the clinical expression of allergies to plant foods. J Allergy Clin Immunol 2006;118:481-488.

4 Datema MR, Zuidmeer-Jongejan L, Asero R, Barreales L, Belohlavkova S, de Blay F, et al: Hazelnut allergy across Europe dissected molecularly: a EuroPrevall outpatient clinic survey. J Allergy Clin Immunol 2015;136:382391.

5 Flores E, Cervera L, Sanz ML, Diaz-Perales A, Fernández J: Plant food allergy in patients with pollinosis from the Mediterranean area. Int Arch Allergy Immunol 2012;159:346-354.

6 Asero R, Antonicelli L, Arena A, Bommarito L, Caruso B, Colombo G, et al: Causes of foodinduced anaphylaxis in Italian adults: a multicentre study. Int Arch Allergy Immunol 2009; 150:271-277.

7 Salcedo G, Sánchez-Monge R, Barber D, Díaz-Perales A: Plant non-specific lipid transfer proteins: an interface between plant defence and human allergy. Biochim Biophys Acta 2007;1771:781-791.

8 Pascal M, Muñoz-Cano R, Reina Z, Palacín A, Vilella R, Picado C, et al: Lipid transfer protein syndrome: clinical pattern, cofactor effect and profile of molecular sensitization to plant-foods and pollens. Clin Exp Allergy 2012;42:1529-1539.

9 Asero R: In patients with LTP syndrome food-specific IgE show a predictable hierarchical order. Eur Ann Allergy Clin Immunol 2014;46:142-146.

10 Scheurer S, Lauer I, Foetisch K, San Miguel Moncin M, Retzek M, Hartz C, et al: Strong allergenicity of Pru av 3, the lipid transfer protein from cherry, is related to high stability against thermal processing and digestion. J Allergy Clin Immunol 2004;114:900-907.

11 Barber D, de la Torre F, Lombardero M, Antépara I, Colas C, Dávila I, et al: Componentresolved diagnosis of pollen allergy based on skin testing with profilin, polcalcin and lipid transfer protein pan-allergens. Clin Exp Allergy 2009;39:1764-1773.

12 Richard C, Leduc V, Battais F: Plant lipid transfer proteins (LTPS): biochemical aspect in panallergen-structural and functional features, and allergenicity. Eur Ann Allergy Clin Immunol 2007;39:76-84
13 Pastorello EA, Robino AM: Clinical role of lipid transfer proteins in food allergy. Mol Nutr Food Res 2004;48:356-362.

14 Asero R, Pravettoni V: Anaphylaxis to plantfoods and pollen allergens in patients with lipid transfer protein syndrome. Curr Opin Allergy Clin Immunol 2013;13:379-385.

15 Morales M, López-Matas MÁ, Moya R, Carnés J: Cross-reactivity among non-specific lipid-transfer proteins from food and pollen allergenic sources. Food Chem 2014;165: 397-402.

16 Tordesillas L, Sirvent S, Díaz-Perales A, Villalba M, Cuesta-Herranz J, Rodríguez R, Salcedo G: Plant lipid transfer protein allergens: no cross-reactivity between those from foods and olive and Parietaria pollen. Int Arch Allergy Immunol 2011;156:291-296.

17 Scala E, Till SJ, Asero R, Abeni D, Guerra EC, Pirrotta L, et al: Lipid transfer protein sensitization: reactivity profiles and clinical risk assessment in an Italian cohort. Allergy 2015; 70:933-943.

18 Gao ZS, Yang ZW, Wu SD, Wang HY, Liu ML, Mao WL, et al: Peach allergy in China: a dominant role for mugwort pollen lipid transfer protein as a primary sensitizer. J Allergy Clin Immunol 2013;131:224-226.e3.

19 Asero R: Co-recognition of lipid transfer protein in pollen and foods in northern Italy: clinicians view. Eur Ann Allergy Clin Immunol 2010;42:205-208

20 Gaier S, Oberhuber C, Hemmer W, Radauer C, Rigby NM, Marsh JT, et al: Pru p 3 as a marker for symptom severity for patients with peach allergy in a birch pollen environment. J Allergy Clin Immunol 2009;124:166-167.

21 Gamboa PM, Cáceres O, Antepara I, SánchezMonge R, Ahrazem O, Salcedo G, et al: Two different profiles of peach allergy in the north of Spain. Allergy 2007;62:408-414.

22 Asero R, Mistrello G, Roncarolo D, Amato S: Relationship between peach lipid transfer protein specific IgE levels and hypersensitivity to non-Rosaceae vegetable foods in patients allergic to lipid transfer protein. Ann Allergy Asthma Immunol 2004;92:268-272.

23 Asero R, Mistrello G, Roncarolo D, Amato S: Detection of some safe plant-derived foods for LTP-allergic patients. Int Arch Allergy Immunol 2007;144:57-63.

24 Sampson HA, Aceves S, Bock SA, James J, Jones S, Lang D, et al: Food allergy: a practice parameter update - 2014. J Allergy Clin Immunol 2014;134:1016-1025.e43.
25 Asero R, Mistrello G, Roncarolo D, Amato S, Caldironi G, Barocci F, et al: Immunological cross-reactivity between lipid transfer proteins from botanically unrelated plant-derived foods: a clinical study. Allergy 2002;57: 900-906

26 Asero R, Mistrello G, Roncarolo D, Amato S: Relationship between peach lipid transfer protein specific IgE levels and hypersensitivity to non-Rosaceae vegetable foods in patients allergic to lipid transfer protein. Ann Allergy Asthma Immunol 2004;92:268-272.

27 Le TM, Bublin M, Breiteneder H, FernándezRivas M, Asero R, Ballmer-Weber B, et al: Kiwifruit allergy across Europe: clinical manifestation and $\operatorname{IgE}$ recognition patterns to kiwifruit allergens. J Allergy Clin Immunol 2013;131:164-171.

28 Bernardi ML, Giangrieco I, Camardella L, Ferrara R, Palazzo P, Panico MR, et al: Allergenic lipid transfer proteins from plant-derived foods do not immunologically and clinically behave homogeneously: the kiwifruit LTP as a model. PLoS One 2011;6:e27856.

29 Sirvent S, Cantó B, Cuesta-Herranz J, Gómez F, Blanca N, Canto G, et al: Act d 12 and Act d 13: two novel, masked, relevant allergens in kiwifruit seeds. J Allergy Clin Immunol 2014; 133:1765-1767.e4.

30 Fernández-Rivas $\mathrm{M}$, Bolhaar $\mathrm{S}$, GonzálezMancebo E, Asero R, van Leeuwen A, Bohle B, et al: Apple allergy across Europe: how allergen sensitization profiles determine the clinical expression of allergies to plant foods. J Allergy Clin Immunol 2006;118:481-488.

31 Javaloyes G, Goikoetxea MJ, García Nuñez I, Aranda A, Sanz ML, Blanca M, et al: Pru p 3 acts as a strong sensitizer for peanut allergy in Spain. J Allergy Clin Immunol 2012;130: 1432-1434.e3.

32 Lombardero M, García-Sellés FJ, Polo F, Jimeno L, Chamorro MJ, García-Casado G, et al: Prevalence of sensitization to Artemisia allergens Art v 1, Art v 3 and Art v 60 kDa: cross-reactivity among Art v 3 and other relevant lipid-transfer protein allergens. Clin Exp Allergy 2004;34:1415-1421.

33 Lauer I, Miguel-Moncin MS, Abel T, Foetisch K, Hartz C, Fortunato D, et al: Identification of a plane pollen lipid transfer protein (Pla a 3 ) and its immunological relation to the peach lipid-transfer protein, Pru p 3. Clin Exp Allergy 2007;37:261-269. 